\title{
Structural relationships between psychosocial risk, relationship quality, need for cognition, and quarantine intentions: the case of the quarantine hotel
}

\author{
Hung-Che $\mathrm{Wu}^{1} \cdot$ Xiaolian $\mathrm{Chen}^{2} \oplus \cdot \mathrm{Ya}^{-}$Yuan $\mathrm{Chang}^{3}$
}

Received: 23 January 2021 / Accepted: 14 July 2021 / Published online: 27 July 2021

(c) The Author(s), under exclusive licence to Springer-Verlag GmbH Germany, part of Springer Nature 2021

\begin{abstract}
This study investigates the relationships between psychosocial risk, relationship quality, need for cognition, and quarantine intentions. Empirical data were collected from quarantine hotel guests in Guangzhou. The results show that depression, anxiety, and stress have a negative influence on satisfaction and that trust and intimacy have a positive influence on satisfaction. Trust has a positive influence on intimacy. Trust and intimacy have a positive influence on commitment. Commitment, satisfaction, and intimacy have a positive influence on quarantine intentions. Intimacy mediates the effect of trust on quarantine intentions. Need for cognition moderates the relationship between satisfaction and quarantine intentions. The theoretical and managerial implications of these results are discussed.
\end{abstract}

Keywords Psychosocial risk · Relationship quality · Need for cognition · Quarantine intentions · Quarantine hotel

Xiaolian Chen

xiaolian413@gmail.com

Hung-Che Wu

wuhungche66@gmail.com

Ya-Yuan Chang

yychang@mail.mcu.edu.tw

1 Independent Researcher, Qingyun Street, Sanming District, Kaohsiung City 807, Taiwan

2 Faculty of International Tourism and Management, City University of Macau, Avenida Padre Tomás Pereira Taipa, Macau, China

3 Department of Hospitality Management, Ming Chuan University, No. 5 De Ming Rd., Gui Shan District, Taoyuan City 333, Taiwan 


\section{Introduction}

With the rapid escalation of positive cases of the coronavirus disease 2019 (COVID-19), hospitals face problems with overcrowding and insufficient isolation space in hospitals (Feng and Cheng 2020). Moreover, there is an increasing worry of frontline healthcare workers and doctors about contracting the virus and infecting loved ones (Rosemberg 2020). In addition, as the COVID-19 pandemic continues, more countries require both citizens and foreign tourists arriving from abroad to enter a mandatory 14-day quarantine period within centralized observation centers or at home. Hotels can be a critical component in the evolution of a local outbreak into a global pandemic and an initial contact point for the import of an impending global pandemic (Hung et al. 2018). Owing to the shortage of quarantine infrastructure, governments have commandeered a number of hotels across the country as part of their strict border controls to control the spread of COVID-19 (Teng et al. 2020). Since guests staying in a quarantine hotel usually come from high-risk areas for COVID-19, they will have the opportunity to be tested for COVID-19, which might cause potential psychosocial risks to both the guests and frontline hotel staff.

Ostovar et al. (2016) indicate that psychosocial risk factors consist of depression, anxiety, stress, and loneliness. People affected by quarantine are likely to display distress due to depression, anxiety, stress, and loneliness perceptions. This distress can be amplified in the face of unclear information and communication that are common in the initial period of disease outbreaks. Wong and Yang (2020) propose that depression, anxiety, stress, and loneliness associated with the risk of contracting COVID-19 become prominent in people's minds while being quarantined in the quarantine hotel. To the best of our knowledge, the psychosocial risk factors remain sparse in the context of quarantine hotels. According to Chayomchai et al. (2020), behavioral intentions positively influence actual quarantine behavior during quarantine time. Satisfying guests generally leads to favorable quarantine intentions (Berg and Lin 2020). However, yet very little research has been conducted regarding guests' intentions when being quarantined in the quarantine hotel during the COVID-19 pandemic (Wong and Yang 2020). Shafiee et al. (2020) propose that relationship quality consists of trust, commitment, intimacy, and satisfaction in the hotel industry. Guney et al. (2010) present that depression and anxiety negatively influence life satisfaction. According to Kim (2019), the higher the level of stress, the lower the level of satisfaction with life. Bergefurt et al. (2019) show that loneliness is also found to influence life satisfaction, indicating that people who feel lonely are less likely to be satisfied with their life. Nora (2019) shows that greater trust enhances customer intimacy. Delgado-Ballester and Munuera-Alemán (2001) suggest that trust plays a key role in increasing commitment. Nora (2019) reveals that stronger customer intimacy enhances relational commitment. Singh (2015) describes that relational satisfaction has a direct positive effect on commitment. Sitorus and Yustisia (2018) present that trust plays a key role in increasing perceptions of satisfaction. $\mathrm{Ng}$ (2010) shows that intimacy is a predictor of satisfaction. However, evidence of 
the relationship between psychosocial risk factors and the dimensions of relationship quality remains sparse in the context of quarantine hotels. Mulia et al. (2021) indicate that trust, commitment, and intimacy are determinants of behavioral intentions during the quarantine period in the COVID-19 crisis. The existing literature has conceptually agreed that intimacy could act as a mediating variable between trust and quarantine intentions (Khalifian and Barry 2016; Ponder et al. 2016; Nora 2019; Shafiee et al. 2020). Wu and Chang (2019) propose that need for cognition moderates the relationship between satisfaction and intentions to be quarantined in the quarantine hotel during the COVID-19 pandemic. Based on the existing literature, very few studies focus on the relationships between the dimensions of relationship quality, need for cognition, and quarantine intentions in the context of quarantine hotels.

To the best of our knowledge, there has been little previous work addressing the relationships between psychosocial risk factors (depression, anxiety, stress, and loneliness), the dimensions of relationship quality (trust, commitment, intimacy, and satisfaction), need for cognition, and quarantine intentions in the context of quarantine hotels. Therefore, this study attempts to examine the relationship between quarantine intentions and their relevant constructs: depression, anxiety, stress, loneliness, trust, commitment, intimacy, satisfaction, and need for cognition, as perceived by guests staying in the quarantine hotel.

This study contributes to the service innovation in the hotel literature from both theoretical and practical perspectives. From the theoretical perspective, this study proposes depression, anxiety, stress, loneliness, trust, commitment, intimacy, satisfaction, need for cognition, and quarantine intentions. It contributes to quarantine hotels for analyzing the relationship between psychosocial risk factors and the dimensions of relationship quality for improving the need for cognition and increasing quarantine intentions. This is a valuable contribution because it helps to improve the overall understanding of guests' perceptions of complex relationships that exist between psychological and service marketing constructs for quarantine hotels. From a managerial perspective, this study provides further insight for hotel managers who provide quarantine services to better understand quarantine intentions by the proposed model, providing useful information to marketing managers who are designing the products and services during the COVID-19 pandemic. The findings of this study will provide guest relationship management with a clear understanding of relevant psychosocial risk factors regarding COVID-19 because they derive from guests who are required to undergo a 14-day quarantine in hotels. Thus, quarantine hotel operators will know exactly where and how to mitigate the negative effect of the psychosocial risk on relationship quality, which in turn leads to guests' intentions to be quarantined in the hotel. Also, they help hotel managers invest more resources in developing the mediating effect of intimacy on the relationship between trust and quarantine intentions, as well as the moderating effect of need for cognition on the relationship between satisfaction and quarantine intentions. 


\section{Review of literature and hypotheses development}

\subsection{Psychosocial risk}

Psychosocial risk is defined as an aspect that could potentially cause physical or psychological harm (Cox and Griffiths 2005). Cooke et al. (2020) propose that depression, anxiety, stress, and loneliness are the major psychosocial risk factors associated with the COVID-19 pandemic. However, psychosocial risk factors receive little attention in the context of quarantine hotels. Sowislo and Orth (2013) define depression as an emotional state characterized by low mood or self-worth and a decline in the ability to enjoy life. Berk et al. (2013) present that depression is associated with a chronic, low-grade inflammatory response and activation of cell-mediated immunity, as well as activation of the compensatory anti-inflammatory reflex system. Hart (2013) describes anxiety as feelings characterized by tension, nervousness, worry, and physical changes (e.g., increased blood pressure, tense muscles). Assessing anxiety is highly contextualized. Thus, there are different types of scales with different objectives. Anxiety has been widely measured in the hospital context (Easton et al. 2016). Sriharan et al. (2020) refer to stress as the degree to which one feels overwhelmed and unable to cope as a result of unmanageable pressures. Stress has been measured in the context of infectious diseases such as severe acute respiratory syndrome and COVID-19, and the most commonly used scale of stress is the seven items within the Depression Anxiety Stress Scale (Zhang et al. 2019). Tiwari (2013) describes loneliness as a state of solitude or being alone. Hawkley and Cacioppo (2010) argue that loneliness is a contested term as it is not only necessarily and simply about being alone but also is a state of mind including but not limited to negative and unpleasant feelings, feelings of inability to find meaning in one's life, and feelings of deficiency in social relations. Given that the context of this study is about guests' experiences of quarantine hotels, therefore, the measurement of depression, anxiety, stress, and loneliness should be tailored for use under the circumstance of the psychosocial risk during the COVID-19 pandemic.

\subsection{Relationship quality}

Relationship quality is defined as the intensity and tightness of a relationship, which play a pivotal role in influencing loyalty (Palmatier et al. 2006). Shafiee et al. (2020) propose that relationship quality is a multi-dimensional construct that comprises trust, commitment, intimacy, and satisfaction in the hotel industry. Based on this framework, relationship quality is defined as an individual's subjective evaluation of his or her partner and relationship (Elizabeth and Ariela 2020). First, trust is defined as the attitude that an agent will help achieve an individual's goals in a situation characterized by uncertainty and vulnerability (Lee and See 2004). Azharghany and Suryaningsih (2021) describe that trust is developed when the consumer feels that the seller (e.g., sharing economy service provider) is fair, benevolent, responsible, and honest. Second, commitment is defined as the act of binding individuals 
intellectually and emotionally toward a specific activity (Sanzo et al. 2012). Many researchers have found commitment to be the key component of establishing and maintaining long-term relationships between business partners (Muñoz-Rivas et al. 2021). Third, intimacy is referred to as a higher level of the organization and customer understanding and attitudinal congruence between (buyers and sellers) partners (Ahmad and Ahmed 2019). It may be expressed through behaviors such as mutual understanding, intimate communication, and giving and receiving emotional support (Noor et al. 2020). Fourth, satisfaction is defined as an individual's feeling of pleasure or disappointment resulting from comparing a product's perceived performance or outcome against his or her expectations (Kotler and Keller 2006). It is considered as a post-purchase response, and experience is important in evaluating satisfaction (Wu and Chang 2019).

In the context of a family relationship, psychosocial risk factors negatively influence relationship satisfaction in a family (Chhabra et al. 2020). Prado-Gascó et al. (2020) propose that the COVID-19-related psychosocial risk factors affect both teachers' and students' health and performance and consequently have negative impacts on their satisfaction of teaching results. In a study of the psychosocial factors related to the COVID-19, Ammar et al. (2020) describe that the enforced COVID-19 home confinement leads to lower life satisfaction. To the best of our knowledge, very few studies focus on identifying whether the COVID-19-related psychosocial risk factors, including depression (H1a), anxiety (H1b), stress (H1c), and loneliness (H1d) in the context of quarantine hotels positively influence satisfaction with quarantine hotels. Therefore, the following hypothesis is proposed:

H1 Psychosocial risk factors $(\mathrm{H} 1 \mathrm{a}-\mathrm{H} \mathrm{H} 1 \mathrm{~d})$ have a negative influence on satisfaction with quarantine hotels.

Delgado-Ballester and Munuera-Alemán (2001) propose that trust plays a key role in generating commitment from customers. Melián-Alzola and Martín-Santana (2020) present that trust in the organization has a positive influence on commitment toward the organization. Shiu-Wan et al. (2019) and Wu et al. (2012) describe that a high level of trust in an exchange partner will lead to a positive affective outcome such as satisfaction in the relationship. Leninkumar (2017) observes an impact of trust on satisfaction, with trust playing an intermediating role in increasing perceptions of satisfaction. Ponder et al. (2016) present that a customer's willingness to form intimate relationships with service providers is influenced by his or her level of trust toward service providers. According to Potdevin et al. (2021), customer intimacy is achieved when organizations have created trusting relationships with customers. Therefore, the following hypotheses are proposed:

H2 Trust has a positive influence on commitment.

H3 Trust has a positive influence on satisfaction.

H4 Trust has a positive influence on intimacy.

Turri et al. (2013) describe that intimacy in human relationships can lead to feelings of commitment. Bügel et al. (2011) propose that customer intimacy contributes to the explanation of commitment in customer relationships. Jun and Cai (2010) propose that customer intimacy is the most influential dimension to achieve high internal satisfaction. Mulia et al. (2021) propose that customer intimacy affects the factors that determine satisfaction. Kantsperger and Kunz (2010) present that 
satisfaction is important for developing commitment. van der Aa et al. (2015) propose that satisfaction with the organization has a positive influence on commitment toward the organization. Therefore, this study has developed the following hypotheses:

H5 Intimacy has a positive influence on commitment.

H6 Intimacy has a positive influence on satisfaction.

H7 Satisfaction has a positive influence on commitment.

\subsection{Need for cognition}

Need for cognition is defined as the need to structure-relevant situations in meaningful and integrated ways and to understand and obtain a reasonable idea of the experiential world (Cohen et al. 1995). It is the tendency in individuals through which they are motivated to engage in and enjoy effortful cognitive activities ( $\mathrm{Su}$ et al. 2021). According to Cacioppo et al. (1996), need for cognition has been shown to be positively related to a number of outcomes that are held to depend on cognitive processing of information, such as absorption in cognitive tasks, cognitive innovativeness, and verbal reasoning scores. Petty et al. (2009) propose that need for cognition has demonstrated positive relationships with reported intrinsic motivation and metacognitive processing.

\subsection{Quarantine intentions}

Croitor et al. (2021) define behavioral intentions as how much a consumer will consider to proceed or not with a future attitude toward a specific service. During the COVID-19 quarantine, once the neighborhood commits to social distancing rules, members will follow each other's behavior (Tejativaddhana et al. 2020). According to Chayomchai et al. (2020), behavioral intentions positively affect the actual use behavior of technologies during quarantine time. Lees et al. (2020) propose that behavioral intentions are related to preventive health behavior during the COVID-19 quarantine. Referring to Chayomchai et al. (2020), the quarantine intentions in this study are defined as the individual tendencies to be quarantined in the quarantine hotel based on the feeling, cognition, or evaluation of experiences. Quarantine intentions can be conceptualized as indicators that signal whether individuals will remain with, or defect from, the quarantine hotel (Wong and Yang 2020).

Prentice et al. (2021) present that trust, commitment, and satisfaction have all been shown to influence the customer's intention to be quarantined in the quarantine hotel. Wang et al. (2021) propose that lodger satisfaction positively influences lodger intention toward quarantine hotel services. Teng et al. (2020) find that customer intimacy plays a role in increasing perceptions of intentions to be quarantined in the quarantine hotel. Harcourt and Adiele (2020) present that customer intimacy contributes significantly to customer intentions to be quarantined in the quarantine hotel. Rosemberg (2020) argues that high customer intimacy is able to encourage customers' intention to be quarantined in a quarantine hotel. Khalifian and Barry (2016) and Nora (2019) propose that trust positively influences intimacy, which in turn leads to intentions to 
be quarantined in the quarantine hotel. Nora (2019) and Ponder et al. (2016) indicate that intimacy could act as a mediating variable between trust and intentions to be quarantined in the quarantine hotel. Wu and Chang (2019) indicate that need for cognition plays a critical role in moderating the relationship between satisfaction and intentions to be quarantined in the quarantine hotel. Wong and Yang (2020) present that need for cognition moderates the effect of satisfaction on intentions to be quarantined in the quarantine hotel. Accordingly, the following hypotheses are proposed:

H8 Trust has a positive influence on quarantine intentions.

H9 Commitment has a positive influence on quarantine intentions.

H10 Satisfaction has a positive influence on quarantine intentions.

H11 Intimacy has a positive influence on quarantine intentions.

H12 Trust has a positive influence on quarantine intentions through intimacy.

H13 Need for cognition moderates the relationship between satisfaction and quarantine intentions.

Based on the literature and the hypotheses listed earlier, we have developed a conceptual framework (see in Fig. 1).

\section{Methods}

\subsection{Measures}

The questionnaire was developed in two parts: (a) survey one focused on how the items of the quarantine intention construct were elicited and (b) survey two focused on how the items of psychosocial risk factors (depression, anxiety, stress, and loneliness), the dimensions of relationship quality (trust, commitment, intimacy, and satisfaction), and need for cognition were developed and validated by prior studies. The final operational definitions are described below.

\subsubsection{Depression}

This study refers to Sowislo and Orth (2013) and defines depression as an emotional state characterized by low mood or self-worth and a decline in the ability to enjoy life.

\subsubsection{Anxiety}

This study refers to Hart (2013) and defines anxiety as feelings characterized by tension, nervousness, worry, and physical changes (e.g., increased blood pressure, tense muscles).

\subsubsection{Stress}

This study refers to Carver and Connor-Smith (2010) and defines stress as the anticipation or experience of encountering demands (e.g., danger/conflict, uncertainty, or pressure) in an individual's goal-related contexts. 


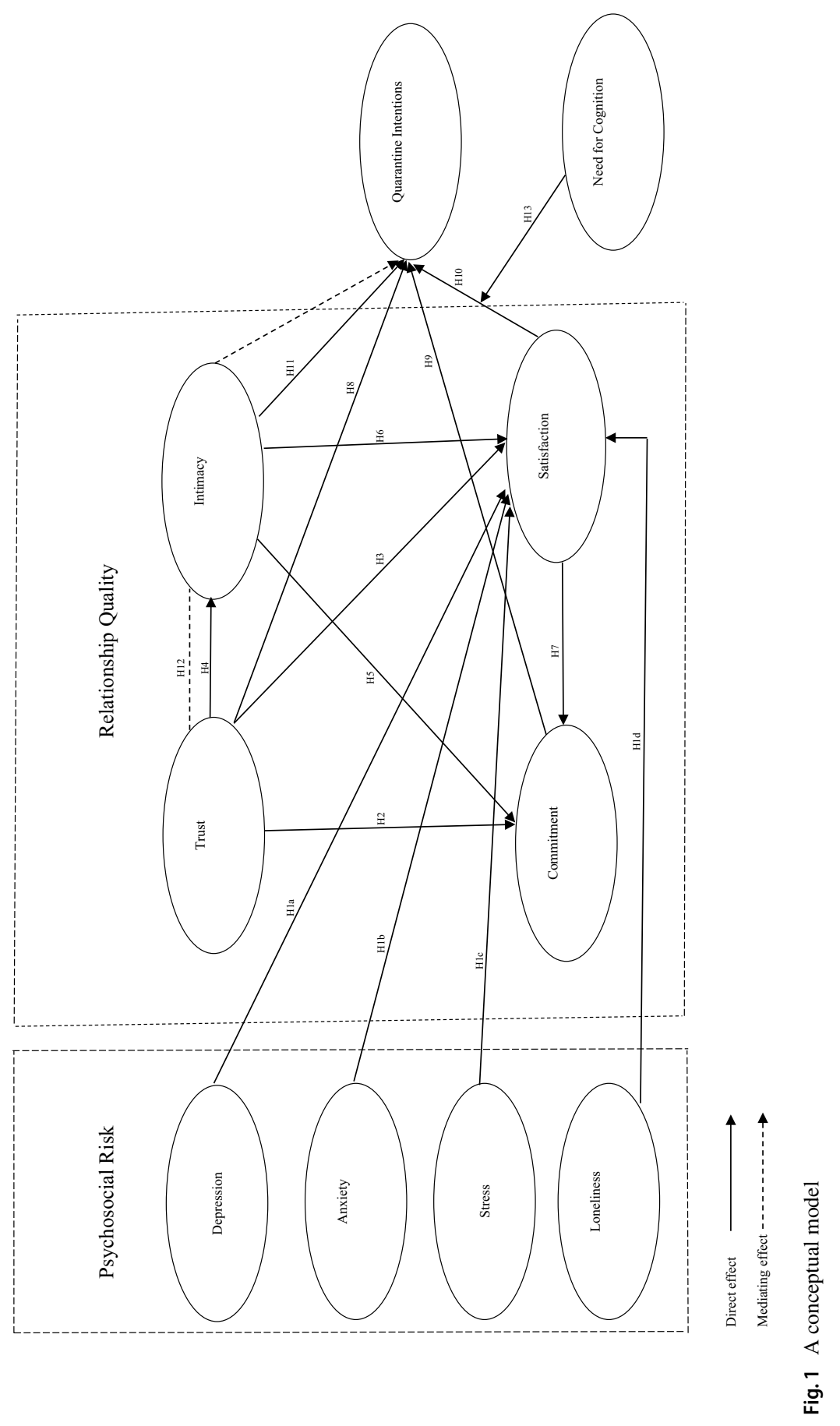




\subsubsection{Loneliness}

This study refers to Tiwari (2013) and defines loneliness as a state of solitude or being alone.

\subsubsection{Trust}

This study refers to Lee and See (2004) and defines trust as the attitude that an agent will help achieve an individual's goals in a situation characterized by uncertainty and vulnerability.

\subsubsection{Commitment}

This study refers to Sanzo et al. (2012) and defines commitment as the act of binding individuals intellectually and emotionally toward a specific activity.

\subsubsection{Intimacy}

This study refers to Ahmad and Ahmed (2019) and defines intimacy as a higher level of the organization and customer understanding and attitudinal congruence between (buyer and seller) partners.

\subsubsection{Satisfaction}

This study refers to Kotler and Keller (2006) and defines satisfaction as an individual's feeling of pleasure or disappointment resulting from comparing a product's perceived performance or outcome against his or her expectations.

\subsubsection{Need for cognition}

This study refers to Cohen et al. (1995) and defines need for cognition as a need to structure-relevant situations in meaningful and integrated ways and a need to understand and form a reasonable idea of the experiential world.

\subsubsection{Quarantine intentions}

This study refers to Chayomchai et al. (2020) and defines quarantine intentions as the individual tendencies to be quarantined in the quarantine hotel based on the feeling, cognition, or evaluation of experiences.

3.1.10.1 Survey one Using the elicitation study and review of the literature, items for the quarantine intention construct and referents were developed. Ajzen (2009) proposes that an elicitation study is applied to obtain new sets of quarantine intentions and important referents for a new context and population. This study employed a focus group including five quarantine hotel managers, six hospitality academics, and eight guests who had been quarantined in the quarantine hotel as an elicitation 
method. In addition, an open-ended survey with 40 guests who had been quarantined in the quarantine hotel was conducted to elicit accessible intentions to be quarantined in the quarantine hotel. A description of the behavior, including target, action, context, and time, was given to the participants (Ajzen 2009). A focus group and an open-ended survey are frequently used as an elicitation method (e.g., Han et al. 2010). Therefore, survey one generated three items for quarantine intentions.

3.1.10.2 Survey two The multiple-item measurement scales, which had been developed and validated by prior studies, were used to measure nine constructs. First, psychosocial risk factors including depression, anxiety, stress, and loneliness were measured with 15 items adapted from Li et al. (2020). Second, trust was measured using six items cited from Estrada-Guillén et al. (2020). Third, the commitment, intimacy, and satisfaction were measured with nine, three, and three items employed by Shafiee et al. (2020), respectively. Finally, need for cognition was measured with eight items adapted from Wu and Chang (2019). All items were measured with a fivepoint Likert's scale $(1=$ strongly disagree and $5=$ strongly agree $)$. To ensure language equivalency, the development of survey two followed the back-translation procedure. The study instrument, originally in English, was translated into Mandarin and then back to English. Survey two was then piloted by four bilinguals to avoid misinterpretation and pre-tested by 50 people who had been quarantined in the quarantine hotel using an offline survey. The results displayed a high level of reliability as Cronbach's $\alpha$ values were greater than 0.70 (Nunnally 1978).

\subsection{Sample design and data collection}

Owing to limited time and manpower, data were collected from the quarantine hotel guests in Guangzhou of Guangdong Province, who were surveyed using the convenience sampling method, from May 1 to July 1, 2020, during the COVID-19 pandemic. In Guangdong Province, Guangzhou is one of the cities with airports receiving international flights. Therefore, it now has approximately 40 quarantine hotels.

The research team contacted the front office managers in the selected quarantine hotels and sent them the link and the quick response (QR) code of the questionnaire survey. The hotel guests aged at least 18 years were invited to scan the QR code and fill out the online survey with their mobile phones when they checked in at the front desk. To reduce the referrals to participate, guests were informed of the survey background, procedures, and purpose. The survey included a declaration of anonymity and confidentiality and the voluntary nature of participation.

The survey participants who understood the survey requirements and who agreed to participate were instructed to complete the questionnaire. The survey obtained the participants' permission through informed consent. The data from the survey remained anonymous and confidential. Questionnaires were distributed to 480 guests at selected quarantine hotels, out of which 430 were returned and deemed fit for the analysis, representing a response rate of $89.58 \%$, which was higher than the recommended $60 \%$ threshold for questionnaire studies (Fincham 
2008). The sample characteristic consisted of 251 males (58.37\%) and 179 female guests $(31.63 \%)$. Table 1 displays the descriptive statistics of the respondents in this study.

Table 1 Respondents' demographic information $(N=430)$

\begin{tabular}{|c|c|c|}
\hline Variable & Number & $\%$ \\
\hline \multicolumn{3}{|l|}{ Gender } \\
\hline Male & 251 & 58.37 \\
\hline Female & 179 & 31.63 \\
\hline \multicolumn{3}{|l|}{ Marital status } \\
\hline Single & 204 & 47.44 \\
\hline Married & 186 & 43.26 \\
\hline Others & 4 & 9.30 \\
\hline \multicolumn{3}{|l|}{ Age } \\
\hline $18-24$ years & 121 & 28.14 \\
\hline $25-34$ years & 98 & 22.79 \\
\hline $35-44$ years & 75 & 17.44 \\
\hline $45-54$ years & 62 & 14.42 \\
\hline $55-64$ years & 57 & 13.26 \\
\hline 65 and over & 17 & 3.95 \\
\hline \multicolumn{3}{|l|}{ Educational level } \\
\hline Secondary school or below & 48 & 11.16 \\
\hline High school & 80 & 18.60 \\
\hline College or university & 231 & 53.72 \\
\hline Graduate school or above & 71 & 16.51 \\
\hline \multicolumn{3}{|l|}{ Occupation } \\
\hline Full time & 126 & 29.30 \\
\hline Part time & 103 & 23.95 \\
\hline Housekeeping & 45 & 10.47 \\
\hline Retiree & 67 & 15.58 \\
\hline Student & 37 & 8.60 \\
\hline Other & 52 & 12.09 \\
\hline \multicolumn{3}{|c|}{$\begin{array}{l}\text { Monthly income before tax (Chinese } \\
\text { Yuan) }\end{array}$} \\
\hline$\leq ¥ 3000$ & 60 & 13.95 \\
\hline$¥ 3001-¥ 5000$ & 143 & 33.26 \\
\hline$¥ 5001-¥ 8000$ & 98 & 22.79 \\
\hline$¥ 8001-¥ 10,000$ & 79 & 18.37 \\
\hline$\geq ¥ 10,000$ & 50 & 11.63 \\
\hline
\end{tabular}

$¥ 6.54=$ US $\$ 1$ (December 27, 2020) 


\section{Data analysis and results}

This study followed several steps to determine whether a measurement issue was caused by common method variance (CMV). First, the samples were collected anonymously to reduce the influence of other factors. Second, before the survey, we clarified to the respondents that there were no correct or incorrect options in the questionnaire, and we asked them to provide their answers according to their actual beliefs (Zhang et al. 2019). Third, we used reverse questions to identify invalid questionnaires. Fourth, Harman's (1976) one-factor test with principal axis and principal-component factoring indicated that the largest factor explained $43.56 \%$ the variance below the specified threshold of 50\% (Podsakoff et al. 2003). Fifth, we applied an unmeasured talent methods factor to confirm the results of CMV. As suggested by Carlson and Kacmar (2000), all measures were added to the researcher's theoretical model as first-order factors of indicators. The degree of fit of the original constructed model $\left(x^{2} / d f\right.$ ratio $=2.74 ; \mathrm{RMSEA}=0.07$, $\mathrm{SRMR}=0.06 ; \quad \mathrm{CFI}=0.98 ; \quad \mathrm{GFI}=0.92 ; \quad \mathrm{IFI}=0.97 ; \quad \mathrm{NFI}=0.98 ; \quad \mathrm{AGFI}=0.86$ ) was much better than the fit after adding method factors $\left(x^{2} / d f\right.$ ratio $=3.49$; $\mathrm{RMSEA}=0.09, \mathrm{SRMR}=0.08 ; \mathrm{CFI}=0.92 ; \mathrm{GFI}=0.86 ; \mathrm{IFI}=0.92 ; \mathrm{NFI}=0.93$; $\mathrm{AGFI}=0.80$ ). All of the above procedures displayed that $\mathrm{CMV}$ was not a serious issue in this study.

To examine whether there were differences of characteristics between the respondents and population, and determine the delegate of responding samples, this study used the suggestion of Armstrong and Overton (1977) and divided the responding basic data into two periods, early responses and late responses. Wherein, early responses were received after the questionnaires were distributed to the respondents one month later; late responses were received from the questionnaires distributed to the respondents 2 months earlier. This paper compared psychosocial risk factors, the dimensions of relationship quality, need for cognition, and quarantine intentions between early responses and late responses by $t$ test. The result indicated that there were no significant differences among early or late responses. Based on this, it was concluded that the sample did not suffer from non-response bias (Cobanoglu et al. 2011).

A two-step approach was used to validate the scales and examine the dynamic relationships among the constructs of the study. First, a confirmatory factor analysis (CFA) as a measurement model was employed to examine depression, anxiety, stress, loneliness, trust, commitment, intimacy, satisfaction, need for cognition, and quarantine intentions. The CFA results displayed that the goodness-of-fit was acceptable with the $x^{2}$ is significant $\left(x^{2}=90.42, x^{2} / d f\right.$ ratio $=2.74$, $p<0.001$ ), the CFI value was 0.98 , RMSEA value 0.07 , GFI value 0.92 , IFI value 0.97 , and NFI value 0.98 . In addition, to test the reliability of depression, anxiety, stress, loneliness, trust, commitment, intimacy, satisfaction, need for cognition, and quarantine intention instruments, the Cronbach's alpha $(\alpha)$ coefficient values were computed. As shown in Table 2, the $\alpha$ coefficient values of depression, anxiety, stress, loneliness, trust, commitment, intimacy, satisfaction, need for cognition, and quarantine intention $(0.87,0.81,0.80,0.83,0.87,0.90,0.78,0.84,0.89$, 


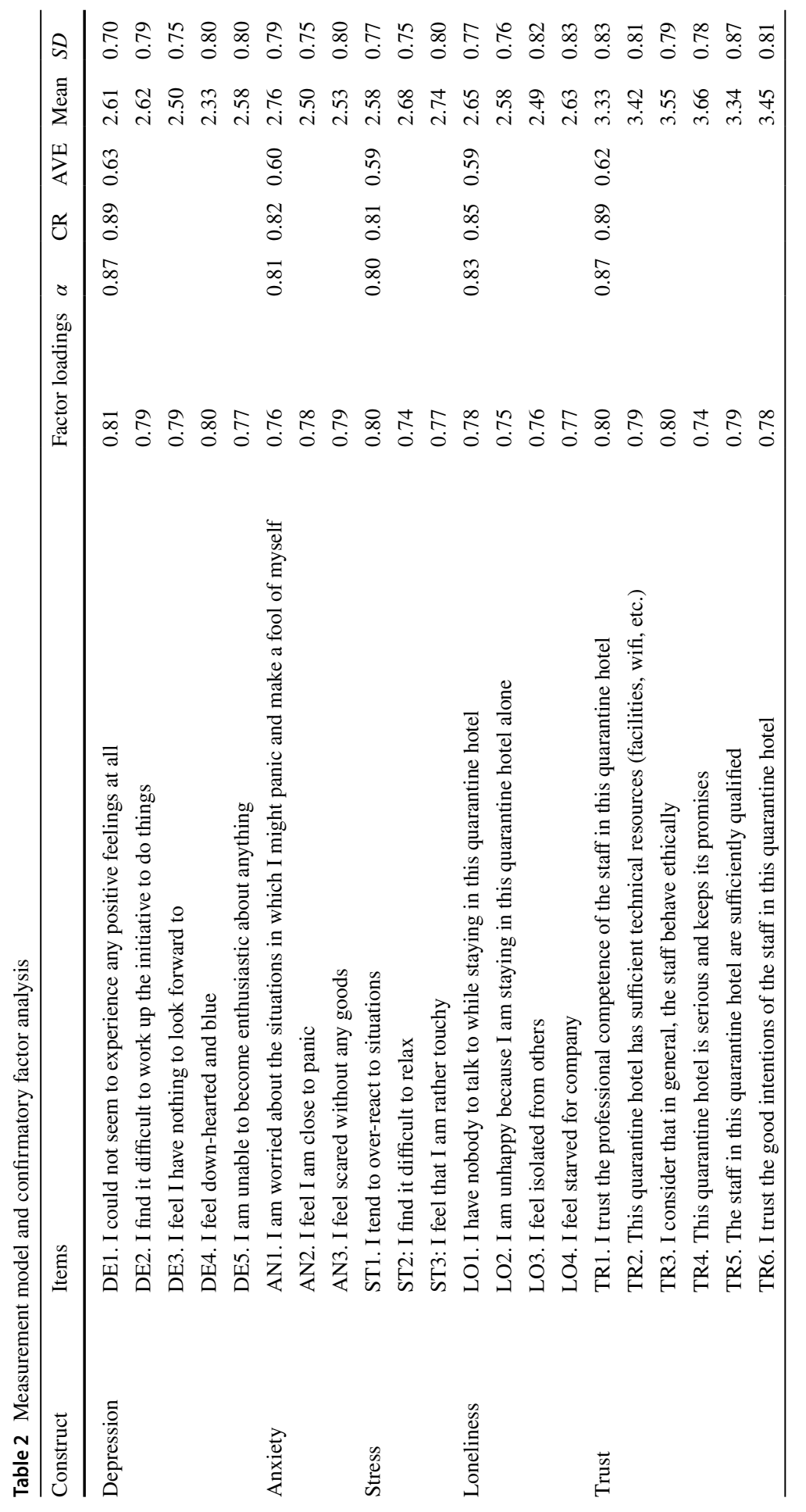




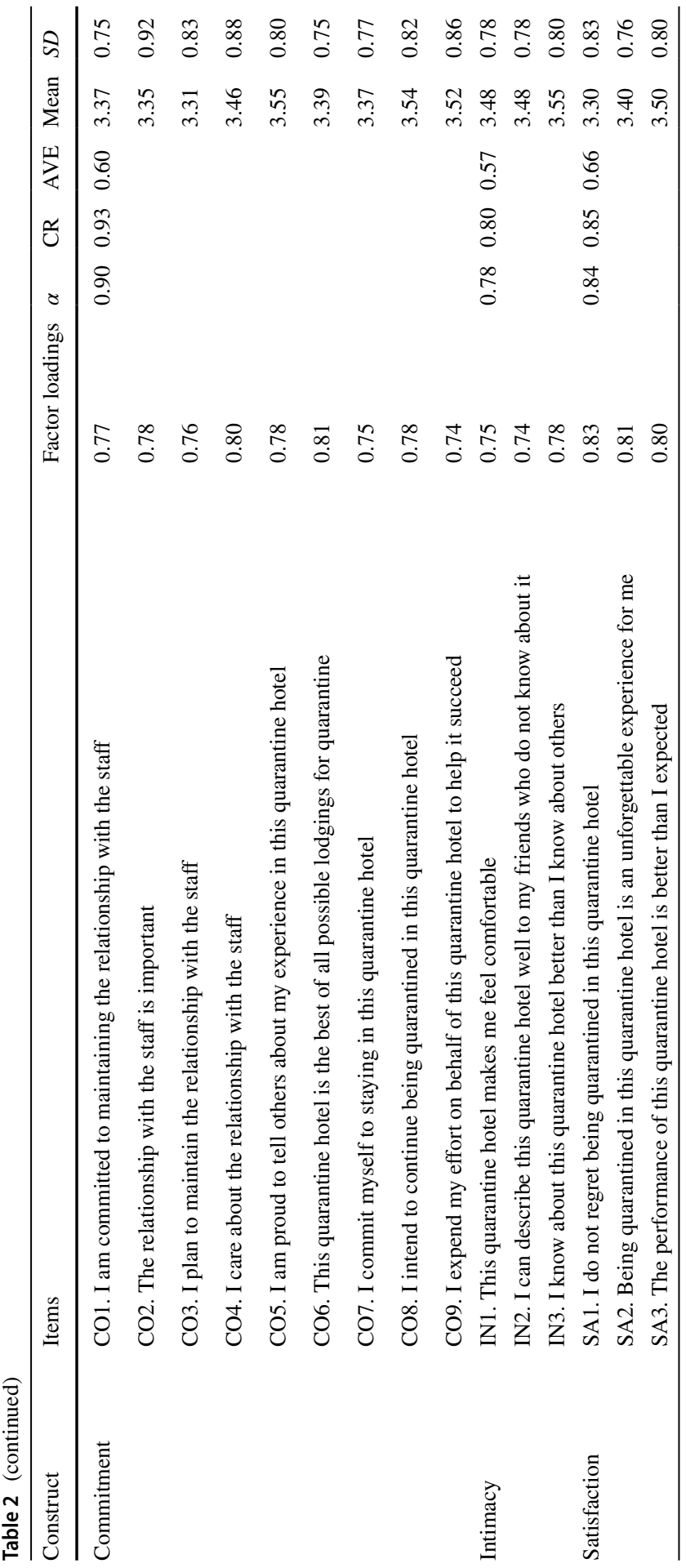




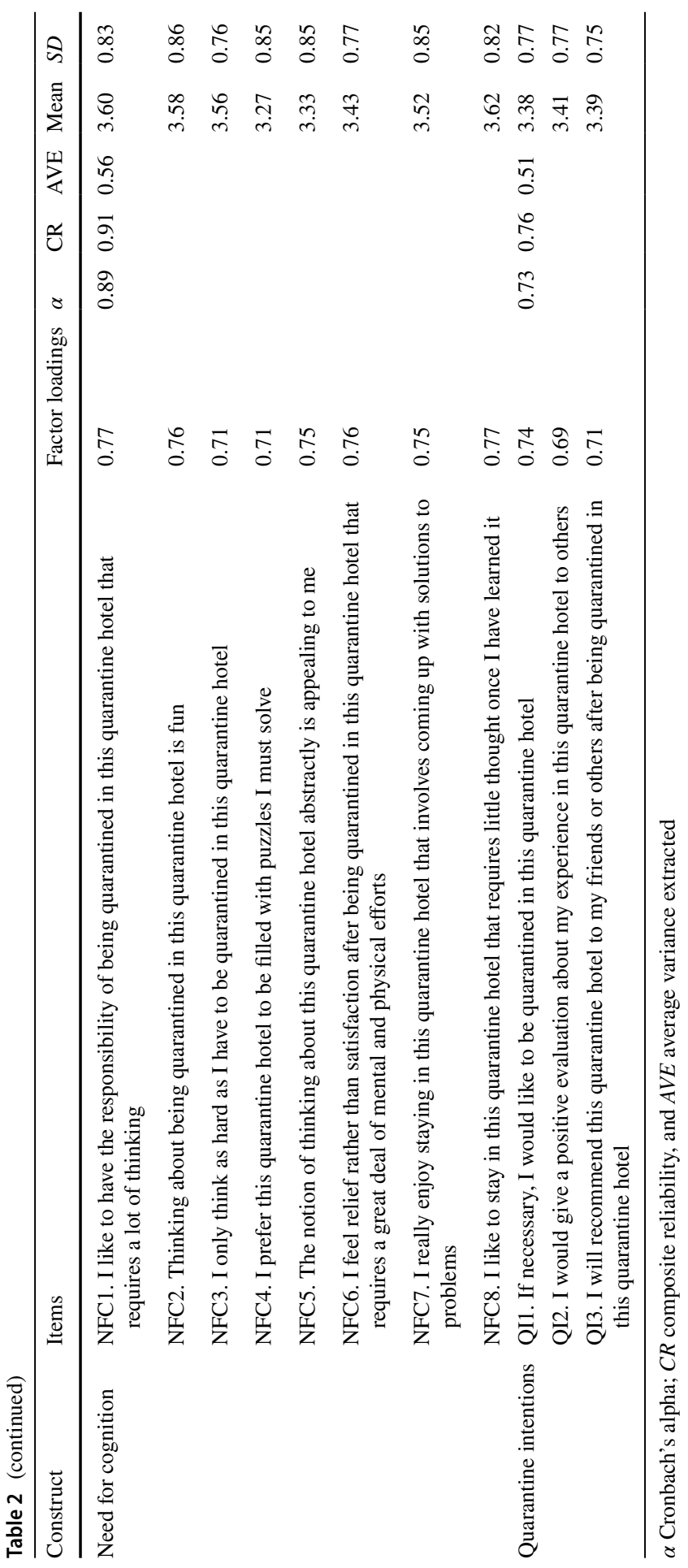


0.73) exceeded the minimum acceptable values of 0.70 suggested by Hair et al. (2010), indicating that all constructs provided a good estimate of internal consistency reliability. Internal consistency of all the constructs was measured by employing composite reliability (CR) as suggested by Hair et al. (2010). For this measure, the threshold criterion is 0.70 (Nunnally 1978) and all the constructs included in this study exceeded the recommended level. Moreover, the convergent validity of the constructs was tested by examining the factor loadings and the average variance extracted (AVE). The value of AVE should exceed 0.50, suggesting adequate convergent validity (Hair et al. 2010); all the constructs included in this study exceeded the recommended level. Table 2 displays the factor loadings and results of $\alpha, \mathrm{CR}$, and AVE for all the constructs. Discriminant validity was assessed based on the correlation matrix of the latent constructs, where the square roots of the AVE values calculated for each construct are reported in boldface along the diagonal. Hair et al. (2010) propose that the average variance shared between a construct and its measures should be greater than the variance shared between the constructs and other constructs in the model. Discriminant validity is given when the diagonal elements (square root AVE) are greater than the off-diagonal elements in the corresponding rows and columns. Overall, all the measures show satisfactory reliability and validity (see Table 3).

Second, the structural model was run to test the relationships between psychosocial risk factors, the dimensions of relationship quality, need for cognition, and quarantine intentions. The results specify the acceptable goodness-of-fit model. The $x^{2}$ were significant $\left(x^{2}=85.14, x^{2} / d f\right.$ ratio $\left.=2.58, p<0.001\right)$, and CFI, GFI, IFI, and NFI values were $0.98,0.93,0.97$, and 0.98 , RMSEA value of 0.06 , indicating that the model was satisfactory (Hair et al. 2010). Structural equation modeling (SEM) and hierarchical regression analysis (HRA) were used to examine the construct relationships.

As displayed in Tables 4 and 5, depression $(\beta=-0.18, t=3.33, p<0.001)$, anxiety $(\beta=-0.16, t=3.17, p<0.01)$, and stress $(\beta=-0.20, t=3.93, p<0.001)$ have a negative influence on satisfaction with quarantine hotels, whereas trust $(\beta=0.15, t=2.54, p<0.05)$ and intimacy $(\beta=0.30, t=5.83, p<0.001)$ have a positive influence on satisfaction with quarantine hotels. As a result, H1a, H1b, $\mathrm{H} 1 \mathrm{c}, \mathrm{H} 3$, and H6 are supported. However, the negative effect of loneliness on satisfaction is insignificant $(\beta=-0.09, t=1.76, p=\mathrm{n} . \mathrm{s}$.), indicating that H1d is not supported. In addition, trust $(\beta=0.10, t=2.25, p<0.05)$, intimacy $(\beta=0.30$, $t=5.83, p<0.001)$, and satisfaction $(\beta=0.39, t=8.01, p<0.001)$ have a positive influence on commitment, showing that $\mathrm{H} 2, \mathrm{H} 5$, and $\mathrm{H} 7$ are supported. Also, trust $(\beta=0.78, t=14.45, p<0.001)$ has a positive influence on intimacy, indicating that $\mathrm{H} 4$ is supported. Moreover, commitment $(\beta=0.35, t=3.64, p<0.001)$, satisfaction $(\beta=0.32, t=5.73, p<0.001)$, and intimacy $(\beta=0.29, t=4.89, p<0.001)$ have a positive influence on quarantine intentions, displaying that $\mathrm{H} 9, \mathrm{H} 10$, and H11 are supported. However, the positive effect of trust on quarantine intentions is insignificant $(\beta=0.08, t=1.86, p=\mathrm{n} . \mathrm{s}$.), showing that $\mathrm{H} 8$ is not supported. This study examines the direct effect of trust on quarantine intentions using SEM alone, indicating that the positive effect of trust on quarantine intentions is significant $(\beta=0.43, t=9.71, p<0.001)$. Furthermore, the mediating effect of 


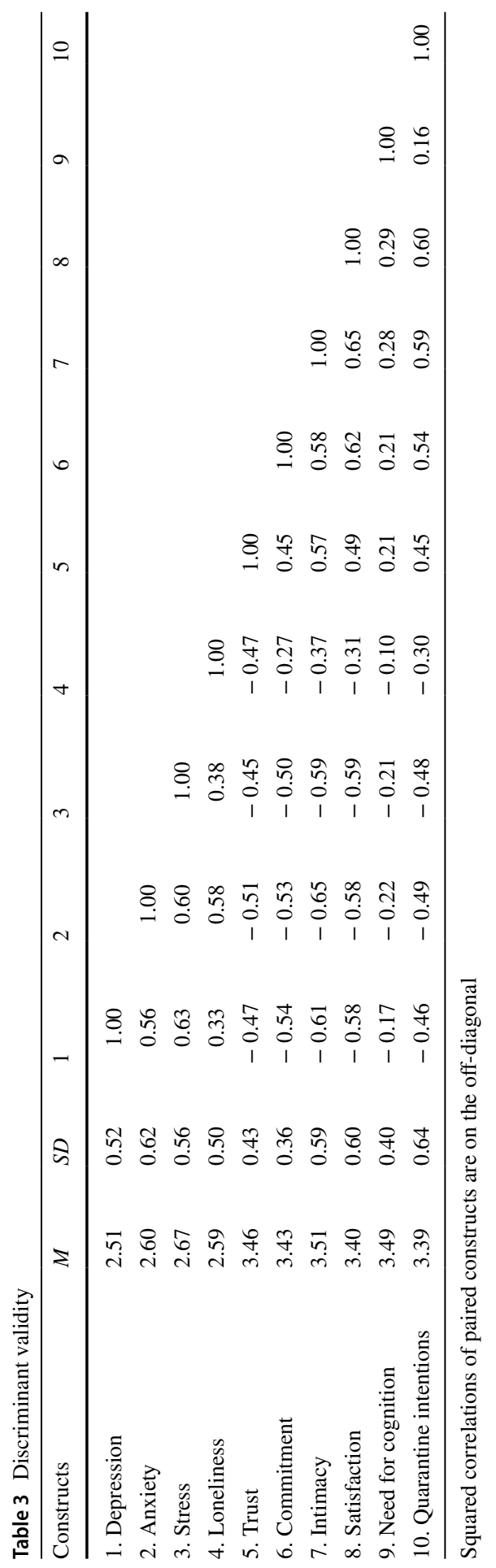


Table 4 Hypothesis test results

\begin{tabular}{llccc}
\hline & Hypothesized path & $\beta$ value & $t$ value & Support \\
\hline H1a: & Depression $\rightarrow$ Satisfaction & $-0.18^{* * *}$ & 3.33 & Yes \\
H1b: & Anxiety $\rightarrow$ Satisfaction & $-0.16^{* *}$ & 3.17 & Yes \\
H1c: & Stress $\rightarrow$ Satisfaction & $-0.20^{* * *}$ & 3.93 & Yes \\
H1d: & Loneliness $\rightarrow$ Satisfaction & -0.09 & 1.76 & No \\
H2: & Trust $\rightarrow$ Commitment & $0.10^{*}$ & 2.25 & Yes \\
H3: & Trust $\rightarrow$ Satisfaction & $0.15^{*}$ & 2.54 & Yes \\
H4: & Trust $\rightarrow$ Intimacy & $0.78^{* * *}$ & 14.45 & Yes \\
H5: & Intimacy $\rightarrow$ Commitment & $0.27 * * *$ & 5.30 & Yes \\
H6: & Intimacy $\rightarrow$ Satisfaction & $0.30^{* * *}$ & 5.83 & Yes \\
H7: & Satisfaction $\rightarrow$ Commitment & $0.39^{* * *}$ & 8.01 & Yes \\
H8: & Trust $\rightarrow$ Quarantine intentions & 0.08 & 1.86 & No \\
H9: & Commitment $\rightarrow$ Quarantine intentions & $0.35^{* * *}$ & 3.64 & Yes \\
H10: & Satisfaction $\rightarrow$ Quarantine intentions & $0.32^{* * *}$ & 5.73 & Yes \\
H11: & Intimacy $\rightarrow$ Quarantine Intentions & $0.29 * * *$ & 4.89 & Yes \\
H12: & Trust $\rightarrow$ Intimacy $\rightarrow$ Quarantine intentions & $0.21^{* * *}$ & 3.94 & Yes \\
\hline
\end{tabular}

$* P<0.05$

** $P<0.01$

$* * * P<0.001$

Table 5 Results of a hierarchical regression analysis for $\mathrm{H} 13$

\begin{tabular}{lc}
\hline Quarantine intentions & \\
\hline Independent variable $^{\text {a }}$ & Model 1 \\
Satisfaction $^{\mathrm{a}}$ & $0.66^{* * *}$ \\
Need for cognition $^{\mathrm{b}}$ & 0.05 \\
Satisfaction $\times$ Need for cognition $^{\text {Intercepts }}$ & $0.25^{*}$ \\
$R$-Square & 1.24 \\
$F$ value & $47.16 \%$ \\
\hline
\end{tabular}

${ }^{\mathrm{a}}$ Independent variable

${ }^{\mathrm{b}}$ Moderating variable

$* \mathrm{p}<0.05$

** $P<0.01$

*** $P<0.001$

intimacy on the relationship between trust and quarantine intentions is significant ( $\beta=0.21, t=3.94, p<0.001)$, indicating that H12 is supported. Moreover, the moderating effect of need for cognition on the relationship between satisfaction and quarantine intentions using HRA is significant $(\beta=0.25, p<0.05)$, indicating that H13 is supported. 


\section{Discussion and implications}

The objective of this study is to elucidate the important role of psychosocial risk in quarantine hotels. More specifically, through a literature review, this paper proposes the psychosocial risk factors (depression, anxiety, stress, and loneliness), the dimensions of relationship quality (trust, commitment, intimacy, and satisfaction), need for cognition, and quarantine intentions. First, this study shows that depression, anxiety, and stress negatively influence satisfaction with quarantine hotels, while trust and intimacy positively influence satisfaction. Second, the study finding indicates that trust has a positive influence on intimacy. Third, the structural results reveal that trust, intimacy, and satisfaction have a positive effect on commitment. Fourth, they find that commitment, satisfaction, and intimacy are predictors of quarantine intentions. Fifth, the study finding shows that intimacy plays a role in mediating the effect of trust on quarantine intentions. Finally, it presents that need for cognition moderates the relationship between satisfaction and quarantine intentions. This study employed 430 quarantine hotel guests in order to evaluate the 13 hypotheses. The data analysis results provide the following significant theoretical and managerial implications.

\subsection{Theoretical implications}

First, this paper represents one of the first studies to introduce the concepts of psychosocial risk factors to quarantine hotel research and to test the concepts of psychosocial risk factors. Second, quarantine hotel guests are currently experiencing quarantine processes that go beyond the accommodation itself only. To strengthen the relationship with guests, quarantine hotels are rethinking guest experience strategies to create consistently engaging and memorable interactions. This paper combines existing psychosocial risk factors, the dimensions of relationship quality, and need for cognition with a novel construct (e.g., quarantine intentions) and then applied them in the hospitality industry. To the best of our knowledge, this is likely to be the first study to examine the relationships between psychosocial risk factors, the dimensions of relationship quality, need for cognition, and quarantine intentions in the context of quarantine hotels. The related literature was reviewed to generate a theoretical model of the factors above.

The objective of this study is partially supported. First of all, the study results show that depression, anxiety, and stress negatively influence satisfaction with quarantine hotels. These findings concur with Cooke et al. (2020), who propose that depression, anxiety, and stress are major determinants of dissatisfaction with life. Second, the study findings reveal that trust and intimacy have a positive influence on satisfaction. This result concurs with the contention of Ngaliman (2018) that trust has an influence on customer satisfaction in the hotel industry. Also, this result is consistent with the proposition of Kim (2020) that intimacy predicts a positive relationship with satisfaction in the hospitality industry. Third, the study finding reveals that trust has a positive influence on intimacy. This result agrees with the proposition of Shafiee et al. (2020) that customer trust after the hotel experience could 
result in positive intimacy. Fourth, the structural results indicate that trust, satisfaction, and intimacy positively influence commitment. These findings are consistent with Yao et al. (2019), who contend that trust and satisfaction in the hotel sector are vital antecedents of commitment. In addition, this result is in accordance with Bügel et al. (2011), who propose that intimacy contributes to customer commitment beyond other factors studied in the relationship investment model. Fifth, the study results reveal that commitment, satisfaction, and intimacy positively influence quarantine intentions. This finding confirms the proposition of Wong and Yang (2020) that commitment and satisfaction are predecessors of the intentions to stay in the quarantine hotel. Also, this result supports Banerjee and Rao (2020), who contend that intimacy has been found to positively impact intentions to be quarantined in the quarantine hotel. Sixth, the study result reveals that intimacy mediates the relationship between trust and quarantine intentions. This finding concurs with the contentions of several studies (Khalifian and Barry 2016; Ponder et al. 2016; Nora 2019; Shafiee et al. 2020) that customers who have high perceptions of trust in services provided by quarantine hotels are more likely to be quarantined in the quarantine hotel because they agree that quarantine hotels can make them feel comfortable to be quarantined in the quarantine hotel during the COVID-19 pandemic. Finally, the structural result displays that need for cognition moderates the relationship between satisfaction and quarantine intentions. This finding is consistent with the contention of $\mathrm{Wu}$ and Chang (2019) that need for cognition moderates the relationship between satisfaction and intentions to be quarantined in the quarantine hotel during the COVID-19 pandemic.

However, the statistical result indicates that the negative effect of loneliness on satisfaction is insignificant. There are two reasons for this discrepancy: One is attributed to the fact that loneliness may not always change in response to different levels of satisfaction in the quarantine hotel. The other is attributed to the fact that the majority of guests may not feel unhappy when they stay in the quarantine hotel alone. Also, the finding reveals that the positive effect of trust on quarantine intentions is insignificant. There are also two reasons for this discrepancy. One explanation for this result is that there are competing influences in trust on the same quarantine intention. The other explanation for this result is that the majority of guests may not trust the staff in the quarantine hotel are sufficiently qualified in order to give a positive evaluation about their experiences in the quarantine hotel to others.

\subsection{Managerial implications}

From a practical perspective, this study can provide further insights for quarantine hotel operators to better understand the dimensions of relationship quality using the proposed model, providing useful information to marketing managers who are designing products and/or services offered by quarantine hotels. The study findings will provide quarantine hotel operators with a clear understanding of the dimensions of relationship quality and their relevant constructs: depression, anxiety, stress, loneliness, need for cognition, and quarantine intentions, as perceived by guests staying in the quarantine hotel. Understanding these relationships will 
equip quarantine hotel marketers and administrators with information they can apply in developing and implementing services and marketing strategies, in order to provide guests with a high-quality experience in a quarantine hotel. Therefore, quarantine hotel operators should know exactly where and how to invest their money to do the most good, considering the scarcity of resources.

This paper assesses the relationships between psychosocial risk factors, the dimensions of relationship quality, need for cognition, and quarantine intentions. First, the statistical results indicate that depression, anxiety, and stress negatively influence satisfaction with quarantine hotels. To increase satisfaction with quarantine hotels, quarantine hotel operators should pay more attention to guests' psychosocial needs and make efforts to reduce guests' perceived psychosocial risk. As a result, quarantine hotels should redesign their room services and amenities, so that being quarantined in a room does not induce guests' anxiety, stress, and depression. For instance, guests should be provided with dance mats with related programs, Yoga mattresses, relevant TV applications, 24-h psychological counseling telephone services and so on.

Second, the statistical results show that trust and intimacy positively influence satisfaction. To increase guest satisfaction, quarantine hotel operators should build guest trust and intimacy. Developing some special in-room programs (such as poker games, movie nights, crafts, music competitions, virtual clubs, and exercises) to facilitate staff-to-guest engagement and interactions and keep guests connected with hotel staff would be a first step to build trust and intimacy, although most of the activities would have to be conducted online. Third, the statistical results show that trust, intimacy, and satisfaction positively influence commitment. To have guests' commitment to the quarantine hotel, quarantine hotel operators should adopt some advanced technologies, such as augmented reality, virtual reality, three-dimensional technology, videos, and live streaming to increase staff-to-guest engagement and interactions and guest satisfaction during those online activities mentioned above. Fourth, the study finding displays that trust positively influences intimacy. To make guests feel comfortable staying in a quarantine hotel, quarantine hotel operators should keep their promises. Fifth, the statistical results reveal that commitment, satisfaction, and intimacy positively influence quarantine intentions. Based on these findings, quarantine hotel operators should make use of instant social media platforms such as QQ, WeChat, and WhatsApp to maintain close interactions with guests, respond to guests' questions in a timely manner, satisfy guests' needs and wants, and build intimate relationships. Sixth, the structural result displays that intimacy mediates the relationship between trust and quarantine intentions. To make guests enjoy using technical resources and recommend the quarantine hotel to others, quarantine hotel operators should provide guests with comfortable environments for their quarantine demands. Finally, the statistical results reveal that need for cognition moderates the relationship between satisfaction and quarantine intentions. As a result, quarantine hotel operators should address guests' need for cognition to facilitate human warmth, sensitivity, and contact, which can improve guest experience in the quarantine hotel and re-choose the hotel for lodging under the quarantine policy. 
However, the research findings display two insignificant statistical results. First, the negative effect of loneliness on satisfaction is insignificant. This may be because most quarantine guests have been used to the practices of self-quarantine and isolation due to the social distance policy, since the battle against COVID-19 has been maintained for such a long time. Second, the positive effect of trust on quarantine intentions is also insignificant. The possible reason for this result is that being quarantined in a designated quarantine hotel is mandatory in the destination in terms of the tourists originating in the areas with increasing COVID-19 cases. Thus, even if the guests trust the service of the quarantine hotel, they would not want to be quarantined in the quarantine hotel again. As such, if quarantine hotel operators were to prioritize which variables deserve special attention in the management of quarantine hotel guests' satisfaction and intentions, perhaps one of the most important aspects that need constant improvement is reducing quarantine guests' perceived psychosocial risk.

\section{Limitations and future research directions}

Despite major contributions to the literature, this study has some limitations that need to be considered. First and foremost, this paper relied on a convenience sample of the guests who had stayed at the selected quarantine hotels of Guangzhou in Guangdong Province between May 1 and July 1, 2020. The analysis and discussion based on the perceptions of the sample respondents may vary if the sample was collected at a different time of year and from a different geographic region. Different sampling methods (e.g., systematic sampling) may add insights into the perceptions of quarantine hotel guests. Second, this study analyzed quarantine hotel guests only. Future studies should focus on the guests who are being quarantined in lodgings such as motels, inns, hostels, and guesthouses (e.g., Wong and Yang 2020) and compare their perceptions of the constructs in the conceptual model of this paper in different contexts of quarantine lodging. Third, an online survey was used to collect data in this paper. Although online surveys provide practical benefits, they may be related to self-selection bias. For future studies, field experimental designs can effectively address self-selection bias. Fourth, during data collection, there may be mediation or moderation of different variables, which is not focused on in this paper. Future studies may consider the inclusion of mediation or moderation of different variables into the process of data collection. Lastly, this study explored four psychosocial risk factors only. Future studies should examine whether fear can be considered to be one of the psychosocial risk factors.

\section{References}

Ahmad M, Ahmed MA (2019) Interpersonal relationship marketing: a dyadic study of firm's customer orientation and customer commitment. Pakistan J Social Issues 10:172-187

Ajzen I (2009) A theory of planned behavior. https://people.umass.edu/aizen/tpb.html. Accessed 3 July 2020. 
Ammar A, Chtourou H, Boukhris O, Trabelsi K, Masmoudi L, Brach M, Mueller P (2020) COVID-19 home confinement negatively impacts social participation and life satisfaction: a worldwide multicenter study. Int J Environ Res Public Health 17(17):1-17

Armstrong JS, Overton TS (1977) Estimating nonresponse bias in mail surveys. J Mark Res 14(3):396-402

Azharghany R, Suryaningsih S (2021) Analysis of stabilization of price fixing for foreign and domestic tourists in the perspective of Islamic business ethics. Jurnal Mantik 4(4):2654-2661

Banerjee D, Rao TS (2020) Sexuality, sexual well being, and intimacy during COVID-19 pandemic: an advocacy perspective. Indian J Psychiatry 62(4):418-426

Berg MB, Lin L (2020) Prevalence and predictors of early COVID-19 behavioral intentions in the United States. Transl Behav Med 10(4):843-849

Bergefurt L, Kemperman A, van den Berg P, Borgers A, van der Waerden P, Oosterhuis G, Hommel M (2019) Loneliness and life satisfaction explained by public-space use and mobility patterns. Int J Environ Res Public Health 16(21):1-20

Berk M, Williams LJ, Jacka FN, O’Neil A, Pasco JA, Moylan S, Allen NB, Stuart AL, Hayley AC, Byrne ML, Maes M (2013) So depression is an inflammatory disease, but where does the inflammation come from? BMC Med 11(1):1-16

Bügel MS, Verhoef PC, Buunk AP (2011) Customer intimacy and commitment to relationships with firms in five different sectors: preliminary evidence. J Retail Consum Serv 18(4):247-258

Cacioppo JT, Petty RE, Feinstein JA, Jarvis WBG (1996) Dispositional differences in cognitive motivation: the life and times of individuals varying in need for cognition. Psychol Bull 119(2):197-253

Carlson DS, Kacmar KM (2000) Work-family conflict in the organization: do life role values make a difference? J Manag 26(5):1031-1054

Carver CS, Connor-Smith J (2010) Personality and coping. Annu Rev Psychol 61:679-704

Chayomchai A, Phonsiri W, Junjit A, Boongapim R, Suwannapusit U (2020) Factors affecting acceptance and use of online technology in Thai people during COVID-19 quarantine time. Manag Sci Lett 10(13):3009-3016

Chhabra J, McDermott B, Li W (2020) Risk factors for paternal perinatal depression and anxiety: a systematic review and meta-analysis. Psychol Men Masculinit 21(4):593-611

Cobanoglu C, Berezina K, Kasavana ML, Erdem M (2011) The impact of technology amenities on hotel guest overall satisfaction. J Qual Assur Hosp Tour 12(4):272-288

Cohen AR, Scotland E, Wolfe DM (1995) An experimental investigation of need for cognition. J Abnorm Soc Psychol 51(2):291-294

Cooke JE, Eirich R, Racine N, Madigan S (2020) Prevalence of posttraumatic and general psychological stress during COVID-19: a rapid review and meta-analysis. Psychiatry Res 292:1-3

Cox T, Griffiths A (2005) The nature and measurement of work-related stress. In: Wilson J, Corlett N (eds) Evaluation of human work: a practical ergonomics methodology, 3rd edn. CRC Press, London, pp 553-573

Croitor E, Werner D, Adam M, Benlian A (2021) Opposing effects of input control and clan control for sellers on e-marketplace platforms. Electron Mark. https://doi.org/10.1007/s12525-021-00465-4

Delgado-Ballester E, Munuera-Alemán JL (2001) Brand trust in the context of consumer loyalty. Eur J Mark 35(11/12):1238-1258

Easton K, Coventry P, Lovell K, Carter LA, Deaton C (2016) Prevalence and measurement of anxiety in samples of patients with heart failure: meta-analysis. J Cardiovasc Nurs 31(4):367-379

Elizabeth AJ (2020) Forecasting relationship quality of Indonesian newlywed individuals: a quantitative study on the role of attachment. Asia Pac J Counsell Psychother 11(2):109-121

Estrada-Guillén M, Monferrer-Tirado D, Moliner-Tena M (2020) Improving relationship quality during the crisis. Serv Ind J 40(3/4):268-289

Feng E, Cheng A (2020) In quarantined Wuhan, hospital beds for coronavirus patients are scarce. https:// www.npr.org/sections/goatsandsoda/2020/02/05/802896668/in-quarantined-wuhan-hospital-bedsfor-coronavirus-patients-are-scarce. Accessed 8 August 2020.

Fincham JE (2008) Response rates and responsiveness for surveys, standards, and the Journal. Am J Pharm Educ 72(2):1-3

Guney S, Kalafat T, Boysan M (2010) Dimensions of mental health: Life satisfaction, anxiety and depression: a preventive mental health study in Ankara University students population. Procedia Soc Behav Sci 2(2):1210-1213

Hair JFJ, Black WC, Babin BJ, Anderson RF (2010) Multivariate data analysis: a global perspective (7th ed). Pearson Education, Upper Saddle River 
Han H, Hsu LTJ, Sheu C (2010) Application of the theory of planned behavior to green hotel choice: testing the effect of environmental friendly activities. Tour Manage 31(3):325-334

Harcourt H, Adiele KC (2020) Customer intimacy adoption and customer retention: a study of bakery firms in Rivers State of Nigeria. Int J Social Sci Manag Res 6(2):27-34

Harman HH (1976) Modern factor analysis, 3rd edn. University of Chicago Press, Chicago

Hart J (2013) Mind-Body therapies for treating anxiety. Alternat Complement Ther 19(6):306-309

Hawkley LC, Cacioppo JT (2010) Loneliness matters: a theoretical and empirical review of consequences and mechanisms. Ann Behav Med 40(2):218-227

Hung KK, Mark CK, Yeung MP, Chan EY, Graham CA (2018) The role of the hotel industry in the response to emerging epidemics: a case study of SARS in 2003 and H1N1 swine flu in 2009 in Hong Kong. Glob Health 14(1):1-7

Jun M, Cai S (2010) Examining the relationships between internal service quality and its dimensions, and internal customer satisfaction. Total Qual Manag Bus Excell 21(2):205-223

Kantsperger R, Kunz WH (2010) Consumer trust in service companies: a multiple mediating analysis. J Serv Theory Pract 20(1):4-25

Khalifian CE, Barry RA (2016) Trust, attachment, and mindfulness influence intimacy and disengagement during newlyweds' discussions of relationship transgressions. J Fam Psychol 30(5):592-601

Kim K (2019) The relationship between perceived stress and life satisfaction of soldiers: moderating effects of gratitude. Asia-Pac J Convergent Res Interchange 5(4):1-8

Kim S (2020) Pseudo-vs. genuine-intimacy: disentangling the intimacy of brand-customer relationships in social media-a hospitality industry perspective (Unpublished doctoral dissertation). Auckland University of Technology, Auckland

Kotler P, Keller KL (2006) Marketing management (12th ed). Pearson Prentice Hall, Upper Saddle River

Lee JD, See KA (2004) Trust in automation: designing for appropriate reliance. Hum Factors 46(1):50-80

Lees J, Cetron JS, Vollberg MC, Reggev N, Cikara M (2020) Intentions to comply with COVID-19 preventive behaviors are associated with personal beliefs, independent of perceived social norms. https://doi. org/10.31234/osf.io/97jry. Accessed 21 Nov 2021.

Leninkumar V (2017) The relationship between customer satisfaction and customer trust on customer loyalty. Int J Acad Res Bus Social Sci 7(4):450-465

Li X, Wu H, Meng F, Li L, Wang Y, Zhou M (2020) Relations of COVID-19-related stressors and social support to Chinese college students' psychological response during the COVID-19 epidemic. Front Psych 11:1-9

Melián-Alzola L, Martín-Santana JD (2020) Service quality in blood donation: satisfaction, trust and loyalty. Serv Bus 14(1):101-129

Mulia D, Usman H, Parwanto NB (2021) The role of customer intimacy in increasing Islamic bank customer loyalty in using e-banking and m-banking. J Islamic Market 12(6):1097-1123

Muñoz-Rivas M, Ronzón-Tirado RC, Redondo N, Cassinello MDZ (2021) Adolescent victims of physical dating violence: why do they stay in abusive relationships? J Interpers Violence. https://doi.org/10. $1177 / 0886260520986277$

$\mathrm{Ng}$ TK (2010) Intimacy, passion, commitment and satisfaction in romantic relationships: The effects of duration, partner and perception (Unpublished doctoral dissertation). City University of Hong Kong, Hong Kong

Ngaliman N (2018) Corporate image mediation between trust and managerial capabilities toward customer satisfaction (empirical study of the customer of familie hotel in Metro City). DERIVATIF: Jurnal Manajemen 12(1):50-59

Noor MN, Holt M, Qureshi A, de Wit J, Bryant J (2020) Sexual risk-taking among homeless young people in Pakistan. Health Soc Care Commun. https://doi.org/10.1111/hsc.13220

Nora L (2019) Trust, commitment, and customer knowledge: clarifying relational commitments and linking them to repurchasing intentions. Manag Decis 57(11):3134-3158

Nunnally J (1978) Psychometric theory, 2nd edn. McGraw-Hill, New York

Ostovar S, Allahyar N, Aminpoor H, Moafian F, Nor MBM, Griffiths MD (2016) Internet addiction and its psychosocial risks (depression, anxiety, stress and loneliness) among Iranian adolescents and young adults: a structural equation model in a cross-sectional study. Int J Ment Heal Addict 14(3):257-267

Palmatier RW, Dant RP, Grewal D, Evans KR (2006) Factors influencing the effectiveness of relationship marketing: a meta-analysis. J Mark 70(4):136-153

Petty RE, Brinõl P, Loersch C, McCaslin MJ (2009) The need for cognition. In: Leary MR, Hoyle RH (eds) Handbook of individual differences in social behavior. Guilford Press, New York, pp 318-329

Podsakoff PM, MacKenzie SB, Lee JY, Podsakoff NP (2003) Common method biases in behavioral research: a critical review of the literature and recommended remedies. J Appl Psychol 88(5):879-903 
Ponder N, Holloway BB, Hansen JD (2016) The mediating effects of customers' intimacy perceptions on the trust-commitment relationship. J Serv Mark 30(1):75-87

Potdevin D, Clavel C, Sabouret N (2021) Virtual intimacy in human-embodied conversational agent interactions: the influence of multimodality on its perception. J Multimodal User Interfaces 15(1):25-43

Prado-Gascó V, Gómez-Domínguez MT, Soto-Rubio A, Díaz-Rodríguez L, Navarro-Mateu D (2020) Stay at home and teach: a comparative study of psychosocial risks between Spain and Mexico during the pandemic. Front Psychol 11:1-12

Prentice C, Hsiao A, Wang X, Loureiro SMC (2021) Mind, service quality, relationship with airlines. J Strateg Mark. https://doi.org/10.1080/0965254X.2021.1894216

Rosemberg MAS (2020) Health and safety considerations for hotel cleaners during Covid-19. Occup Med 70(3):214-215

Sanzo MJ, Álvarez LI, Rey M, García N (2012) Perceptions of top management commitment to innovation and R\&D-marketing relationship effectiveness: Do they affect CSR? Ann Public Cooperat Econ 83(3):383-405

Shafiee MM, Tabaeeian RA, Khoshfetrat A (2020) Tourist engagement and citizenship behavior: the mediating role of relationship quality in the hotel industry. Tour Hosp Res 20(4):481-492

Shiu-Wan H, Cheng MJ, Chiu PC (2019) Do antecedents of trust and satisfaction promote consumer loyalty in physical and virtual stores? A Multi-Channel View Serv Bus 13(1):1-23

Singh S (2015) The impact of service satisfaction, relational satisfaction and commitment on customer loyalty in logistics outsourcing relationship. J Supply Chain Manag Syst 4(1):58-71

Sitorus T, Yustisia M (2018) The influence of service quality and customer trust toward customer loyalty: the role of customer satisfaction. Int J Qual Res 12(3):639-654

Sowislo JF, Orth U (2013) Does low self-esteem predict depression and anxiety? A meta-analysis of longitudinal studies. Psychol Bull 139(1):213-240

Sriharan A, Ratnapalan S, Tricco AC, Lupea D, Ayala AP, Pang H, Lee D (2020) Stress, burnout and depression in women in health care during COVID-19 Pandemic: rapid scoping review. medRxiv. https://doi. org/10.1101/2020.07.13.20151183

Su Y, Lee DKL, Xiao X, Li W, Shu W (2021) Who endorses conspiracy theories? A moderated mediation model of Chinese and international social media use, media skepticism, need for cognition, and COVID-19 conspiracy theory endorsement in China. Comput Hum Behav 120:1-10

Tejativaddhana P, Suriyawongpaisal W, Kasemsup V, Suksaroj T (2020) The roles of village health volunteers: COVID-19 prevention and control in Thailand. Asia Pac JHealth Manag 15(3):18-22

Teng YM, Wu KS, Lin KL (2020) Life or livelihood? Mental health concerns for quarantine hotel workers during the COVID-19 pandemic. Front Psychol 11:1-4

Tiwari SC (2013) Loneliness: a disease? Indian J Psychiatry 55(4):320-322

Turri AM, Smith KH, Kemp E (2013) Developing affective brand commitment through social media. J Electron Commer Res 14(3):201-214

van der Aa Z, Bloemer J, Henseler J (2015) Using customer contact centres as relationship marketing instruments. Serv Bus 9(2):185-208

Wang KY, Ma ML, Yu J (2021) Understanding the perceived satisfaction and revisiting intentions of lodgers in a restricted service scenario: evidence from the hotel industry in quarantine. Serv Bus 15(2):335-368

Wong IA, Yang FX (2020) A quarantined lodging stay: the buffering effect of service quality. Int J Hosp Manag 91:1-9

Wu HC, Chang YY (2019) What drives brand supportive intentions? Mark Intell Plan 37(5):497-512

Wu CW, Huarng KH, Fiegantara WuPC (2012) The impact of online customer satisfaction on the yahoo auction in Taiwan. Serv Bus 6(4):473-487

Yao T, Qiu Q, Wei Y (2019) Retaining hotel employees as internal customers: effect of organizational commitment on attitudinal and behavioral loyalty of employees. Int J Hosp Manag 76:1-8

Zhang SN, Li YQ, Liu CH, Ruan WQ (2019) How does authenticity enhance flow experience through perceived value and involvement: the moderating roles of innovation and cultural identity. J Travel Tour Mark 36(6):710-728

Publisher's Note Springer Nature remains neutral with regard to jurisdictional claims in published maps and institutional affiliations. 